\title{
Differential effects of 5-HTTLPR genotypes on mood, memory, and attention bias following acute tryptophan depletion and stress exposure
}

\author{
Christine Firk • C. Rob Markus
}

Received: 30 June 2008 / Accepted: 26 November 2008 / Published online: 16 December 2008

(C) The Author(s) 2008. This article is published with open access at Springerlink.com

\begin{abstract}
Rationale Polymorphisms of the serotonin transporter gene (5-HTTLPR) may be associated with increased vulnerability to acute tryptophan depletion (ATD) and depression vulnerability especially following stressful life events.

Objective The aim of the present study was to investigate the effects of ATD in subjects with different 5-HTTLPR profiles before and after stress exposure on affective and cognitive-attentional changes.

Materials and methods Eighteen subjects with homozygotic short alleles $\left(\mathrm{S}^{\prime} / \mathrm{S}^{\prime}\right)$ and 17 subjects with homozygotic long alleles $\left(\mathrm{L}^{\prime} / \mathrm{L}^{\prime}\right)$ of the 5-HTTLPR participated in a double-blind, placebo-controlled, crossover design to measure the effects of ATD on mood, memory, and attention before and after acute stress exposure.

Results ATD lowered mood in all subjects independent of genotype. In $\mathrm{S}^{\prime} / \mathrm{S}^{\prime}$ genotypes, mild acute stress increased depressive mood and in $\mathrm{L}^{\prime} / \mathrm{L}^{\prime}$ genotypes increased feelings of vigor. Furthermore, $\mathrm{S}^{\prime} / \mathrm{S}^{\prime}$ genotypes differed from $\mathrm{L}^{\prime} / \mathrm{L}^{\prime}$ genotypes on measures of attention independent of treatment and memory following ATD.

Conclusions Polymorphisms of the 5-HTTLPR differentially affect responses to mild stress and ATD, suggesting greater vulnerability of $\mathrm{S}^{\prime} / \mathrm{S}^{\prime}$ carriers to serotonergic manipulations and supporting increased depression vulnerability.
\end{abstract}

C. Firk $(\bowtie) \cdot$ C. R. Markus

Department of Clinical Psychological Science,

Faculty of Psychology and Neuroscience, Maastricht University, P.O. Box 616, 6200 MD Maastricht, The Netherlands

e-mail: christine.firk@psychology.unimaas.nl

C. R. Markus

Department of Neuropsychology and Psychopharmacology,

Maastricht University,

Maastricht, The Netherlands
Keywords Serotonin transporter gene polymorphism . 5-HTTLPR · Major depression · Tryptophan depletion · Stress

\section{Introduction}

Dysregulation of the serotonergic system has been implicated in the pathophysiology of depression (Maes and Meltzer 1995). This is based on studies reporting lower plasma availability of the serotonin (5-HT) precursor tryptophan for uptake into the brain, reduced cerebrospinal fluid concentration of the 5-HT metabolite 5-hydroxyindoleacetic (5-HIAA) and decreased platelet 5-HT uptake in depressed patients, suggesting diminished brain 5-HT uptake and metabolism (Maes and Meltzer 1995; Neumeister et al. 2004). The level of 5-HT in the synaptic cleft is mainly regulated by the 5-HT transporter (5-HTT), which is targeted by most antidepressants (Meyer et al. 2004; Suhara et al. 2003; Voineskos et al. 2007). Interestingly, the human 5-HTT gene, located on chromosome 17q11.1-q12 (Lesch et al. 1994), contains a 5-HTT-linked polymorphic region (5-HTTLPR) with two functional variants: the short (s) form and the long (1) form (Greenberg et al. 1999; Heils et al. 1996). The s form of this variant is less active, resulting in reduced transcriptional efficiency of the 5-HTT gene, decreased 5-HTT expression, and reduced 5-HT uptake relative to the 1 form (Greenberg et al. 1999; Heils et al. 1996). The s allele has been associated with increased risk of depression (Collier et al. 1996; Gonda et al. 2005, 2006; Joiner et al. 2003), poorer responses to the antidepressant effects of SSRIs (Serretti et al. 2007; Smeraldi et al. 1998), increased vulnerability to tryptophan depletion (Neumeister et al. 2002; Roiser et al. 2006), and abnormal emotional processing (Hariri et al. 2002; Marsh et al. 2006). 
A direct association between 5-HTTLPR genotypes and depression-related phenotypes appears to be relatively weak (Lotrich and Pollock 2004). Roiser et al. (2005) only found abnormal emotional processing in 3,4 methylenedioxymethamphetamine (MDMA, or Ecstasy) users carrying the $\mathrm{s}$ allele. MDMA prevents uptake of 5-HT and stimulates the release of 5-HT, causing long-term changes to the 5-HT system. This suggests that $\mathrm{s}$ allele carriers may only have a predisposition to serotonergic vulnerability that may be unmasked through challenges to the serotonergic system. This is also in line with contemporary theoretical models of gene involvement in depression that postulate that genetic vulnerability does not affect depression directly; rather, 5HTTLPR may enhance susceptibility for depression particularly in the face of severe life events or stressful experiences, which may also challenge the brain serotonergic system (Firk and Markus 2007). Hence, depression is often preceded by stress (Van Praag 2004), and epidemiological studies have already demonstrated a positive association between the s allele of the 5-HTTLPR and a depressive reaction to stressful life events (e.g., Caspi et al. 2003; for a recent review see Uher and McGuffin 2008). This is in line with the hypothesis that stress may cause depression due to complex interactions between the neuroendocrine stress system and the serotonergic system, particularly in individuals with a biological (genetic) vulnerability related to their serotonergic system (Firk and Markus 2007; Van Praag 2004). Although explorations of the involvement of interactions between serotonergic vulnerability in s allele 5-HTTLPR and stress in the onset of affective symptoms are a major challenge in biological psychiatry today, this interaction has not yet been experimentally investigated.

On the other hand, the relatively small direct association between 5-HTTLPR genotypes and depression-related phenotypes may also be explained by recently identified functional variants within the 1 allele $\left(\mathrm{L}_{\mathrm{A}}\right.$ and $\left.\mathrm{L}_{\mathrm{G}}\right)$ that may underestimate the effect of 5-HTTLPR. This is because the $\mathrm{L}_{\mathrm{G}}$ allele has a low rate of 5-HTT expression comparable to the $s$ allele and is relatively common in Caucasian and African American populations (Hu et al. 2006; Zalsman et al. 2006).

One accepted method to study behavioral and cognitive effects of transiently reduced 5-HT availability in humans is the acute tryptophan depletion (ATD) strategy (for a review see Fusar-Poli et al. 2006; Young et al. 1985). In this procedure, brain 5-HT is reduced through depletion of plasma tryptophan (TRP, a precursor of 5-HT) availability for uptake into the brain by intake of a TRP-free amino acid mixture that contains all of the essential amino acids except for TRP. This raises incorporation of TRP into protein synthesis and reduces TRP relative to the sum of the other large neutral amino acids (LNAAs) with which TRP competes for uptake into the brain (i.e., Fernstrom and Wurtman 1971; Gessa et al. 1974; Maes and Meltzer 1995; Moja et al. 1991). Evidence for reduced 5-HT neurotransmission after ATD comes from studies measuring 5-HT metabolites (5-HIAA) in cerebrospinal fluid (Carpenter et al. 1998; Williams et al. 1999). In addition, there is also plenty of evidence showing that the ATD procedure is the most suitable method to study brain 5-HT vulnerability. For instance, mood-lowering effects of tryptophan depletion are clearly found in depressive patients in remission (Delgado et al. 1990, 1999; Moreno et al. 2000; Ruhe et al. 2007), whereas in healthy individuals such mood-lowering effects seem to depend on the 5-HTTLPR genotype (Neumeister et al. 2002, 2006; Roiser et al. 2007; Walderhaug et al. 2007) and family history of depression (Benkelfat et al. 1994; Klaassen et al. 1999; Neumeister et al. 2002). Individuals with a positive family history of depression are more vulnerable to the mood-lowering effects of ATD than individuals without a family history of depression, suggesting an (innate) vulnerability of the serotonergic system in relatives of depressive patients (Benkelfat et al. 1994; Klaassen et al. 1999; Neumeister et al. 2002). However, the effects of ATD on mood in individuals with different 5HTTLPR profiles are contradictory. Neumeister et al. (2002) reported mood lowering in healthy s allele carriers, in particular in those with a positive family history of depression. Walderhaug et al. (2007) found mood lowering following ATD only in women homozygous for the 1 and s allele, whereas other studies did not find mood-lowering effects at all (Marsh et al. 2006; Roiser et al. 2007). Therefore, we suggest that the possession of the s allele, which is very common in the population, may not alone increase risk, but may induce enhanced susceptibility to ATD only in the context of stress.

The aim of the present study was to investigate the effects of ATD in subjects with different 5-HTTLPR profiles before and after stress exposure on affective and cognitive-attentional changes that are thought to be critical in the etiology and maintenance of depression. A selective attention and memory bias for negative information is the most commonly recognized characteristic of depression and depression vulnerability (e.g., Bradley et al. 1995; Mogg and Bradley 2005; Rinck and Becker 2005). For instance, depressive patients show memory biases for negative information in explicit memory free recall tasks (e.g., Bradley et al. 1995; Lim and Kim 2005) and slowed responses to happy words compared to sad words during affective go/no-go (AGNG) tasks (Murphy et al. 1999; Erickson et al. 2005). In addition, comparable attentional biases are also found in healthy individuals following ATD, further suggesting that serotonergic factors are particularly involved (Murphy et al. 2002). Based on the literature and the data reviewed above, we hypothesized that the 5- 
HTTLPR genotype mediates ATD- and stress-induced changes in mood and cognitive-behavioral indications of affective biases. To our knowledge, this is the first time the depressogenic effects of reducing brain 5-HT by ATD are investigated in 5-HT-vulnerable s allele 5-HTTLPR carriers before and after stress exposure.

\section{Materials and methods}

\section{Participants}

Undergraduate students at Maastricht University $(N=200)$ completed a screening questionnaire concerning general information (health, smoking and drinking habits, caffeine consumption, use of psychoactive drugs, past and present treatment with medication, weight and height, eating habits, and more). Furthermore, the Beck Depression Inventory (BDI; Beck et al. 1961) was completed to verify the absence of depressive symptomatology.

Participants were excluded if they reported chronic and current illness; history of psychiatric or medical illness; family history of depression; medication use; metabolic, hormonal, or intestinal diseases; irregular diets or deviant eating habits; drug use; or excessive (more than 10 units per week) alcohol use. Participants' health was checked with standardized medical questionnaires that were evaluated by a trained doctoral-level psychologist under the supervision of a medical doctor. We acknowledge that, although participants reported not having any medical illness, a medical examination might have been a likely additional method to further ensure participants' physical health. Participants included in the study revealed normal body mass indexes (BMI in $\mathrm{kg} / \mathrm{m}^{2}$ between 19 and 26), were non-smokers and were requested not to use alcohol before or during the study.

From the subjects showing interest in taking part in the experiment and fulfilling to the in- and exclusion criteria, 86 participants were invited to attend an initial buccal sample extraction session. During this session, buccal cell samples were taken via swabs to genotype all individuals for 5-HTTLPR. Participants were compensated $(€ 5)$ for participation in this buccal sample extraction phase of the study. All subjects had to give informed consent to participate during this buccal DNA extraction session.

Participants with the $\mathrm{S} / \mathrm{S}, \mathrm{S} / \mathrm{L}_{\mathrm{G}}$, or $\mathrm{L}_{\mathrm{G}} / \mathrm{L}_{\mathrm{G}}$ genotype classified as $\mathrm{S}^{\prime} / \mathrm{S}^{\prime}$ and participants with the $\mathrm{L}_{\mathrm{A}} / \mathrm{L}_{\mathrm{A}}$ genotype classified as $\mathrm{L}^{\prime} / \mathrm{L}^{\prime}$ were selected for the experiment and received oral and written information about the study. Eighteen subjects with the $\mathrm{S}^{\prime} / \mathrm{S}^{\prime}$ genotype and 17 subjects with the $\mathrm{L}^{\prime} / \mathrm{L}^{\prime}$ genotype completed the experiment. The $\mathrm{S}^{\prime} / \mathrm{S}^{\prime}$ group and the $\mathrm{L}^{\prime} / \mathrm{L}^{\prime}$ group did not differ with respect to sex, age, BMI, or BDI scores (all $p>0.05$ ). Demographic characteristics are presented in Table 1.

The study was approved by the Medical Ethics Committee of the Academic Hospital Maastricht (CTCM azM; Maastricht; The Netherlands), and the procedures followed were in accordance with the Helsinki Declaration of 1975 as revised in 1983. All subjects gave their informed consent to participate in the experiment and were paid $150 €$ for participation.

\section{Design}

A placebo-controlled, double-blind, crossover design was used. During two experimental sessions, subjects were monitored for affective processing before and after acute stress exposure either following intake of a TRP-free (TRP-) or a TRP-containing balanced (TRP+) amino acid mixture. The order of presentation of the TRP- and TRP+ condition was counterbalanced within groups and both experimental sessions were separated by at least 1 week. Before and $4.5 \mathrm{~h}$ after intake of the amino acid mixtures, blood samples were taken to measure the effect of ATD on plasma amino acid concentrations and the TRP/LNAA ratio. Female subjects were tested in the follicular phase of their menstrual cycle (days 4-10) or when actually taking oral contraceptives.

\section{Procedure}

All participants were instructed to fast overnight; only water or tea without sugar was permitted. On each experimental morning, participants arrived for testing at 08:30 A.M., 09:00 A.M., 09:30 A.M., and 10:00 A.M., respectively, and a first blood sample was taken to obtain baseline plasma TRP and LNAA levels. A second blood sample was drawn $4.5 \mathrm{~h}$ after intake of the amino acid mixture (TRP- or TRP+) to assess changes in total TRP concentrations and TRP/LNAA ratios. At baseline and $4.5 \mathrm{~h}$ following intake of the amino acid mixture, subjects completed a survey measuring vegetative side effects. Five hours after administration of the amino acid mixture,

Table 1 Demographic characteristics

\begin{tabular}{lll}
\hline & \multicolumn{2}{l}{ Genotype } \\
\cline { 2 - 3 } & $\mathrm{S}^{\prime} / \mathrm{S}^{\prime}$ & $\mathrm{L}^{\prime} / \mathrm{L}^{\prime}$ \\
\hline Women & 17 & 18 \\
Men & 2 & 2 \\
Age & $19.6(1.7)$ & $19.5(1.8)$ \\
BMI & $22.0(1.8)$ & $21.4(2.2)$ \\
BDI & $2.7(2.4)$ & $2.8(2.6)$ \\
\hline
\end{tabular}

Values represent mean (SD) 
participants' mood was assessed with the Profile of Mood States (POMS; Wald and Mellenbergh 1990) and the Positive and Negative Affect Scale (PANAS; Watson et al. 1988). Mood assessment was followed by the affective go/no-go task (to measure attentional biases) and the emotional related free recall task (to measure memory biases). Then, participants were exposed to an uncontrollable stress task (Markus-Peters Arithmetic (MPA) task), again followed by mood assessment and the affective go/ no-go task and the emotional related free recall task. Further, two pre-stress salivary cortisol samples were taken (at $4.5 \mathrm{~h}\left(t_{-30}\right)$ and immediately before the MPA task $\left(t_{0}\right)$ ) and two post-stress cortisol samples were taken (immediately after the MPA task $\left(t_{+20}\right)$ and 10 min after finishing the MPA task $\left.\left(t_{+30}\right)\right)$ to measure stress-related activation of the hypothalamic-pituitary-adrenal (HPA) axis. Between intake of the amino acid mixture and exposure to laboratory tasks, the subjects were able to study or to read magazines in a separate private room. They had free access to water and decaffeinated tea. Two hours after administration of the amino acid mixture, they received a standardized proteinpoor lunch as previously used in ATD studies (Riedel et al. 1999; Sobczak et al. 2002a, b). At the end of each test day, subjects received a high protein snack and bananas, which are natural sources of L-tryptophan to facilitate a quick recovery from possible negative effects of ATD.

\section{Acute tryptophan depletion}

A reduction in brain 5-HT was accomplished by ATD through the use of a tryptophan-free collagen-protein (CP) amino acid drink (Blokland et al. 2004; Evers et al. 2005; Sambeth et al. 2008). To obtain a drinkable mixture, $100 \mathrm{~g}$ of the protein powder was mixed with $200 \mathrm{ml}$ of tap water. During the PLC condition the intake of the mixture was directly followed by ingestion of four capsules containing 1.2 g L-TRP (Sigma, Zwijndrecht; The Netherlands), whereas during the ATD condition, intake was directly followed by ingestion of four capsules containing lactose (all capsules were taken with a little water). See Table 2 for the amino acid composition of the different conditions (Evers et al. 2005).

This ATD method differs from the classic methodology by including a gelatin-based hydrolyzed CP that contains the entire range of amino acids (except for L-TRP) in the form of peptides. After administration, these peptides are decomposed into amino acids and the mechanism of depletion is identical to the classical ATD method.

\section{Stress exposure}

A mental arithmetic task, performed under noise stimulation, was used as an uncontrollable stress situation
Table 2 Composition (grams) of the gelatin-based protein (all values are grams per $100 \mathrm{~g}$ of each mixture)

\begin{tabular}{lcc}
\hline & TRP- & TRP+ \\
\hline Phenylalanine & 1.9 & 1.9 \\
Tyrosine & 0.4 & 0.4 \\
Valine & 2.1 & 2.1 \\
Leucine & 3 & 3 \\
Isoleucine & 1.4 & 1.4 \\
Tryptophan & 0.1 & 1.3 \\
Serine & 3.1 & 3.1 \\
Glycine & 22.5 & 22.5 \\
Histidine & 0.5 & 0.5 \\
Arginine & 8.8 & 8.8 \\
Threonine & 1.1 & 1.1 \\
Alanine & 9.3 & 9.3 \\
Proline & 13.3 & 13.3 \\
Methionine & 0.6 & 0.6 \\
Cystein & 0.2 & 0.2 \\
Lysine & 3.6 & 3.6 \\
Hydroxyproline & 12.1 & 12.1 \\
Hydroxylysine & 1.4 & 1.4 \\
Aspartic acid + asparagines & 9.3 & 9.3 \\
Glutamic acid + glutamine & 5.2 & 5.2 \\
\hline
\end{tabular}

(Markus-Peters Arithmetic task). Subjects were given 18 successive 1-min trials during which they had to solve a specific number of multiple choice mental arithmetic problems (the criterion) under time constraints, while at the same time continuous 75,80 , or $85 \mathrm{~dB}$ industrial noise was presented to them through headphones. They were led to believe that the intensity of the noise depended on their performance; if they failed the criterion, the noise intensity was chosen by the computer during the next trial; if they met the criterion, they could choose the intensity of the noise. In fact, the criterion was manipulated so that all subjects continued to fail on each trial. This task has been demonstrated to induce psychological and physiological stress and to be perceived as highly uncontrollable (Markus et al. 1998, 2000a, b; Peters et al. 1998). In the present study, an adapted version of the MPA was used during which subjects had to perform under audience observation. Furthermore, subjects were told that a video analysis of their performance was conducted to analyze their nonverbal behavior.

Subjective mood ratings

Profile of mood states Changes in mood were measured using the Dutch shortened version of the POMS questionnaire (Wald and Mellenbergh 1990), offered at the computer-screen as a VAS scale ranging from "strongly disagree" to "strongly agree". The POMS comprises five 
different subscales for mood, ranging from anger, depression, fatigue, and tension that refer to a negative mood state, to vigor concerning a positive mood.

Positive and Negative Affect Scale The PANAS (Watson et al. 1988) consists of two 10-item mood scales, a positive mood scale and a negative mood scale. The 20 items are randomly presented on a computer screen and participants have to respond on a scale ranging from 1 (totally disagree) to 5 (totally agree).

\section{Emotional related free recall}

To test emotionally related immediate and delayed free recall, an adapted version of the 30 Word Learning Test (30 WLT) was used (e.g., Smeets et al. 2006; Sobczak et al. $2002 \mathrm{~b}$ ). The 30 WLT is an adapted version of the Rey Auditory Verbal Learning Task (Lezak 2004) In this test, participants are presented with a list of 30 words (ten negative, ten positive, and ten neutral words matched for frequency, word length, and emotional valence, chosen from Hermans and De Houwer's (1994) list of Dutch words that have been rated for familiarity and affectivity) in random order. Each word was presented on the computer monitor for $3 \mathrm{~s}$ with an inter-stimulus interval of $1 \mathrm{~s}$. The participants had to rate how relevant each word was to their personal concerns on a scale ranging from 1 (not at all relevant) to 5 (extremely relevant). Following the encoding task, the participants were given $2 \mathrm{~min}$ to complete an immediate written recall task. A delayed recall took place after $30 \mathrm{~min}$. Four comparable lists (matched for frequency, word length, and emotional valence) were used and presentation order was counterbalanced across participants.

\section{Affective go/no-go}

A modified version of the affective go/no-go task described by Murphy et al. (1999) was used in the present study. In this task, happy and sad words are presented on the screen oneby-one for $300 \mathrm{~ms}$ followed by an inter-stimulus interval of $900 \mathrm{~ms}$ during which participants must make or withhold a button press response on the basis of the emotion of the word. The task comprises two practice blocks and 12 experimental blocks. Each block contains 18 words (nine happy words and nine sad words), and subjects are instructed that they must respond either to the happy words or to the sad words before each block. Every two blocks, the targets and the distractors change, words that were previously targets become distractors, and words that were previously distractors become targets (SSHHSSHHSSH HSS or HHSSHHSSHHSSHH). Due to this arrangement, shift blocks and non-shift blocks can be studied.
Vegetative side effects

In order to measure possible side effects of the amino acid mixtures, a list (five-point scales) of vegetative side effects was completed before and $4.5 \mathrm{~h}$ after intake. The list contained the following items: feeling cold, feeling hot, dizziness, perspiration, blurred vision, nausea, palpitations, dry mouth, and abdominal complaints.

Biochemical measurements

Plasma samples Blood samples were collected in $5 \mathrm{ml}$ Vacutainer tubes containing sodium heparin for amino acid measurements. The sodium heparin tube was centrifuged at $5,000 \mathrm{rpm}$ for $10 \mathrm{~min}$ at $4^{\circ} \mathrm{C}$. Subsequently, the supernatants were directly stored at $-80^{\circ} \mathrm{C}$ until analysis. Plasma amino acid analyses were conducted with HPLC, making use of a 2-3- $\mu \mathrm{m}$ Bischof Spherisorb ODS II column. The plasma tryptophan ratio was calculated by dividing the plasma tryptophan concentration by the sum of the other large neutral amino acids, i.e., valine, isoleucine, leucine, tyrosine, and phenylalanine.

Salivary cortisol Cortisol samples were obtained by using the Salivette sampling device (Sarstedt ${ }^{\circledR}$, Etten-Leur, The Netherlands). With this procedure, saliva was collected in small cotton swabs and stored $\left(-25^{\circ} \mathrm{C}\right)$ immediately upon collection until centrifugation. Saliva samples were centrifuged at $2,650 \times g_{\max }$ for $3 \mathrm{~min}$ at $20^{\circ} \mathrm{C}$. Salivary free cortisol levels were determined in duplicate by direct radioimmunoassay (University of Liège, Belgium), including a competition reaction between ${ }^{125}$ iodohistamine-cortisol and anti-cortisol serum made against the 3-CMO-BSA conjugate. After incubation of $100 \mu \mathrm{l}$ of saliva at $4^{\circ} \mathrm{C}$ overnight, separation of free and antibody-bound ${ }^{125}$ iodohistaminecortisol was performed via a conventional "second antibody" method. In order to reduce sources of variability, all samples were analyzed in the same assay.

Buccal cells for polymorphism assessment Buccal cell samples for measuring triallelic variants of the 5-HTTlinked polymorphic region (5-HTTLPR) were obtained using sterile swabs (Omni Swabs, Whatman's Hertogenbosch, The Netherlands). Genomic DNA was isolated from buccal swabs using QIAamp DNA Mini Kits from Qiagen (Westburg, Leusden, The Netherlands) for determination of the 5-HTTLPR genotype. Briefly, genotyping was performed using the polymerase chain reaction protocol according to Wendland et al. (2006) with the oligonucleotide primers 5'-TCCTCCGCTTTGGCGCCTCTTCC-3' and 5'-TGGGGGTTGCAGGGGAGATCCTG-3'. Triallelic variants were reclassified into a biallelic model as follows: $\mathrm{S} / \mathrm{S}$, $\mathrm{S} / \mathrm{L}_{\mathrm{G}}$, and $\mathrm{L}_{\mathrm{G}} / \mathrm{L}_{\mathrm{G}}$ were classified as $\mathrm{S}^{\prime} / \mathrm{S}^{\prime}$ and $\mathrm{L}_{\mathrm{A}} / \mathrm{L}_{\mathrm{A}}$ as $\mathrm{L}^{\prime} / \mathrm{L}^{\prime}$ 
(Neumeister et al. 2006; Walderhaug et al. 2007; Zalsman et al. 2006).

\section{Statistical analysis}

The main research questions were analyzed by means of repeated measures multivariate and univariate analyses of variance (MANOVA and ANOVA) by using the General Linear Model (SPSS 12.0 for Windows) with one between-subjects factor genotype $\left(\mathrm{S}^{\prime} / \mathrm{S}^{\prime}\right.$ vs. $\left.\mathrm{L}^{\prime} / \mathrm{L}^{\prime}\right)$ and two within-subjects factors treatment (TRP+ vs. TRP-) and stress (pre-stress vs. post-stress) or time ( $t_{0}$ vs. $t_{4.5}$ or $t_{5}$; cortisol analysis: time $\left(t_{-30}\right.$ vs. $t_{0}$ vs. $t_{+20}$ vs. $\left.\left.t_{+30}\right)\right)$ on the several dependent measures. Order was included as centered covariate. For the subjective mood ratings, we conducted two repeated measures ANOVAs with genotype $\left(\mathrm{S}^{\prime} / \mathrm{S}^{\prime}\right.$ vs. $\left.\mathrm{L}^{\prime} / \mathrm{L}^{\prime}\right)$ as the between-subjects factor and treatment (TRP+ vs. TRP-) as the within-subjects factors for the subjective mood ratings. To investigate the effects of treatment and the effects of stress separately, we included time ( $t_{0}$ vs. $t_{5}$ ) in the first analysis and stress (pre-stress vs. post-stress) in the second analysis as within-subjects factor. For the affective go/no-go task, valence (positive vs. negative) and shift (shift blocks vs. non-shift blocks) were included as within-subjects factors. For the emotional related free recall, valence (negative vs. neutral vs. positive) was included as a within-subjects variable. Greenhouse-Geisser corrected $p$ values are reported when the sphericity assumption is not met. All statistics are evaluated at a two-tailed significance level of 5\%. Post hoc analyses for significant interactions were assessed by paired and unpaired $t$ tests to aid interpretation; corrections for multiple comparisons were not carried out.

\section{Results}

Plasma amino acids (total TRP and TRP/LNAA ratio)

For TRP concentrations a significant treatment $\times$ time interaction was found $[F(1,32)=224.87, p<0.001]$, reflecting a decrease from $t_{0}$ to $t_{4.5}$ by $79 \%$ after TRP- and an increase from $t_{0}$ to $t_{4.5}$ by $68 \%$ after TRP+ administration. Analysis of the plasma TRP/LNAA ratio revealed a significant treatment $\times$ time interaction $[F(1,32)=269.59$, $p<0.001]$ with a $77 \%$ decline in plasma TRP/LNAA after TRP - and an increase from $t_{0}$ to $t_{4.5}$ by $62 \%$ after TRP+ (see Fig. 1). No other main or interaction effects were found including genotype.

\section{Cortisol}

Repeated measures analysis of variance only revealed a main effect of time $[F(3,30)=4.02, p=0.016]$ showing a
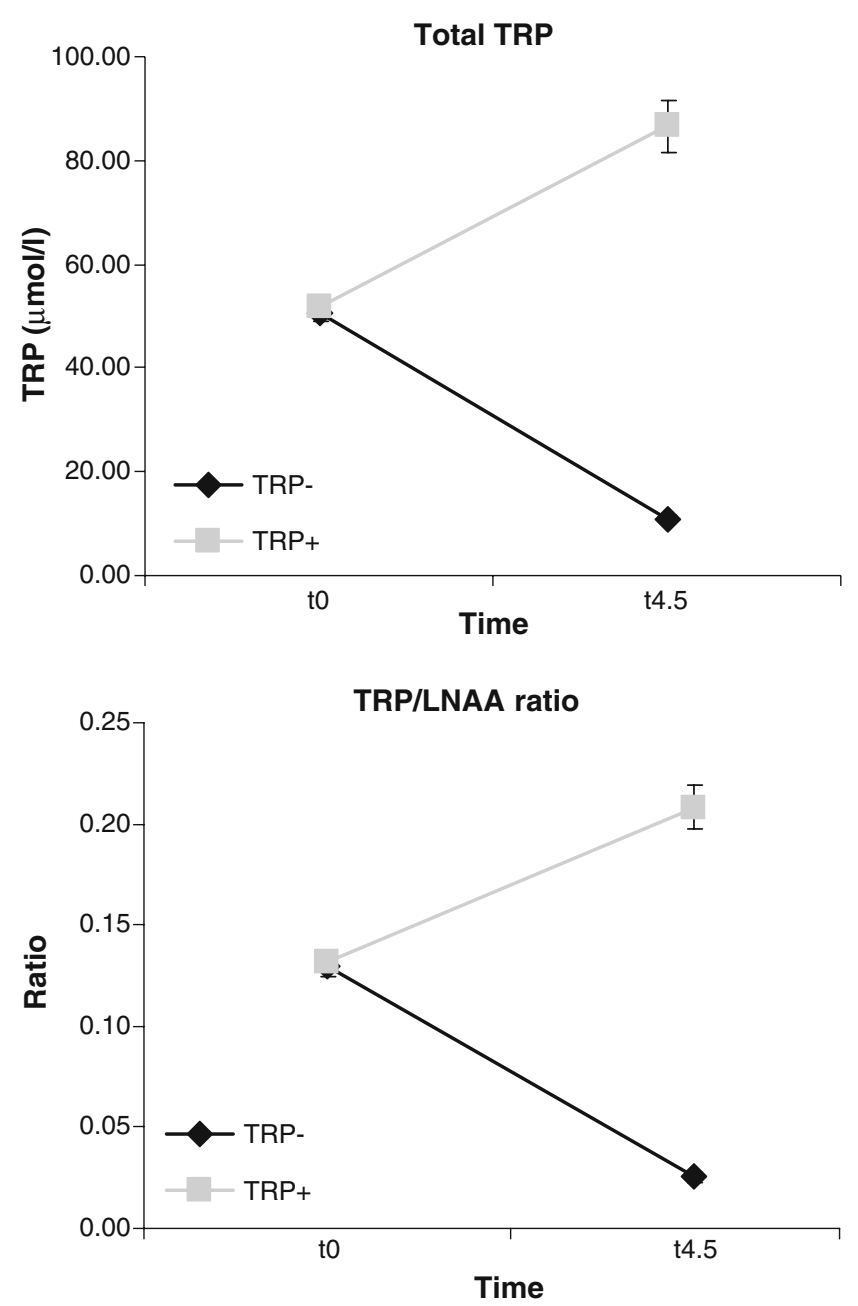

Fig. 1 Plasma total TRP concentrations and TRP/LNAA ratio for the TRP - and TRP+ conditions. For TRP concentrations, we found a significant decrease from $t_{0}$ to $t_{4.5}$ after TRP $-[t(34)=24.56, p<0.001]$ and a significant increase from $t_{0}$ to $t_{4.5}$ by $68 \%$ after TRP $+[t(34)=7.58$, $p<0.001]$. For the TRP/LNAA ratio, we found a significant decrease from $t_{0}$ to $t_{4.5}$ after TRP $-[t(34)=23.07, p<0.001]$ and a significant increase from $t_{0}$ to $t_{4.5}$ by $68 \%$ after TRP $+[t(34)=7.63, p<0.001]$

slight but significant decline in cortisol concentrations $t_{+20}$ to $t_{+30}$ (from $2.4 \pm 0.2$ to $2.2 \pm 0.2 \mathrm{nmol} / \mathrm{L}$ ).

Vegetative side effects

No significant main or interaction effects were found.

Subjective mood ratings

Data for the subjective mood rating scales are presented in Table 3.

POMS In the first analysis, multivariate analysis revealed a main effect of time $[F(5,28)=12.52, p<0.001]$ with higher 
anger and fatigue scores and lower tension scores at $t_{5}$. Further, univariate analysis of the POMS revealed a treatment $\times$ time interaction of the vigor subscale $[F(1,32)=$ 7.28, $p=0.011]$ and fatigue subscale $[F(1,32)=5.35, p=$ 0.027] reflecting a stronger decrease in vigor ratings following TRP - than TRP $+[t(34)=2.74, p=0.01]$ and a stronger increase in fatigue ratings following TRP- than TRP $+[t(34)=2.32, p=0.026]$ (see Fig. 2).

In the second analysis, multivariate analysis showed a main effect of stress $[F(5,28)=3.81, p=0.009]$ and a significant stress $\times$ genotype interaction $[F(5,28)=3.96, p=$ $0.008]$ (see Fig. 3). Further, univariate analysis showed that the main effect of stress originated from the subscale anger $[F(1,32)=12.39, p=0.001]$ and fatigue $[F(1,32)=4.51, p=$ $0.041]$, reflecting an increase in anger post-stress compared to pre-stress and a decrease in fatigue post-stress compared to pre-stress. The stress $\times$ genotype interaction originated from the depression subscale $[F(1,32)=8.24, p=0.007]$ and the vigor subscale $[F(1,32)=13.12, p=0.001]$. This interaction was explored with a one-way multivariate analysis including the vigor and depression subscale for each genotype, indicating an increase in depressive mood after stress in the $\mathrm{S}^{\prime} / \mathrm{S}^{\prime}$ group $[F(1,16)=5.38, p=0.034]$ only and an increase in vigor after stress in the $\mathrm{L}^{\prime} / \mathrm{L}^{\prime}$ group $[F(1,15)=$ 12.61, $p=0.003$ ] only (Fig. 3).

PANAS In the first analysis, we found a treatment $\times$ time interaction $[F(1,32)=6.94, p=0.013]$ on the positive scale, indicating a decrease in positive mood regardless of genotype following TRP $-[t(34)=2.57, p=0.015]$ but not following TRP $+[t(34)<1, \mathrm{~ns}]$ (see Fig. 2). No effects were found for the negative scale of the PANAS.

In the second analysis, only a significant effect of stress $[F(1,32)=4.28, p=0.047]$ was found on the negative scale, reflecting higher negative mood scores post-stress compared to pre-stress regardless of treatment and genotype.

\section{Affective go/no-go}

Mean values and standard deviations are presented in Table 4.

Reaction time Analysis of reaction time (RT) data revealed a main effect of stress $[F(1,32)=5.73, p=0.023]$, indicating longer RTs post-stress compared to pre-stress, and a main effect of Shift $[F(1,32)=11.98, p=0.002]$ with faster RTs for shift blocks than non-shift blocks. This shift effect was qualified by a treatment $\times$ shift interaction $[F(1,32)=5.5, p=$ 0.025 ], indicating faster RTs for shift trials than non-shift trials in the TRP + condition only $[t(34)=4.31, p<0.001]$ and a valence $\times$ shift interaction $[F(1,32)=4.71, p=0.038]$, indicating longer RTs for sad non-shift trials compared to sad shift trials $[t(34)=3.88, p<0.001]$. Analysis also revealed a

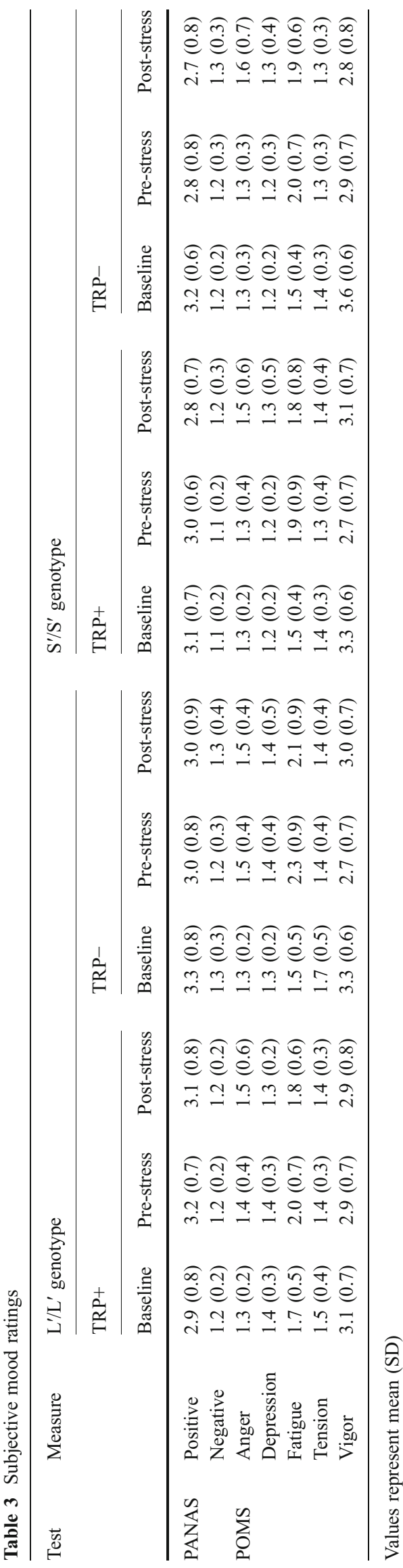



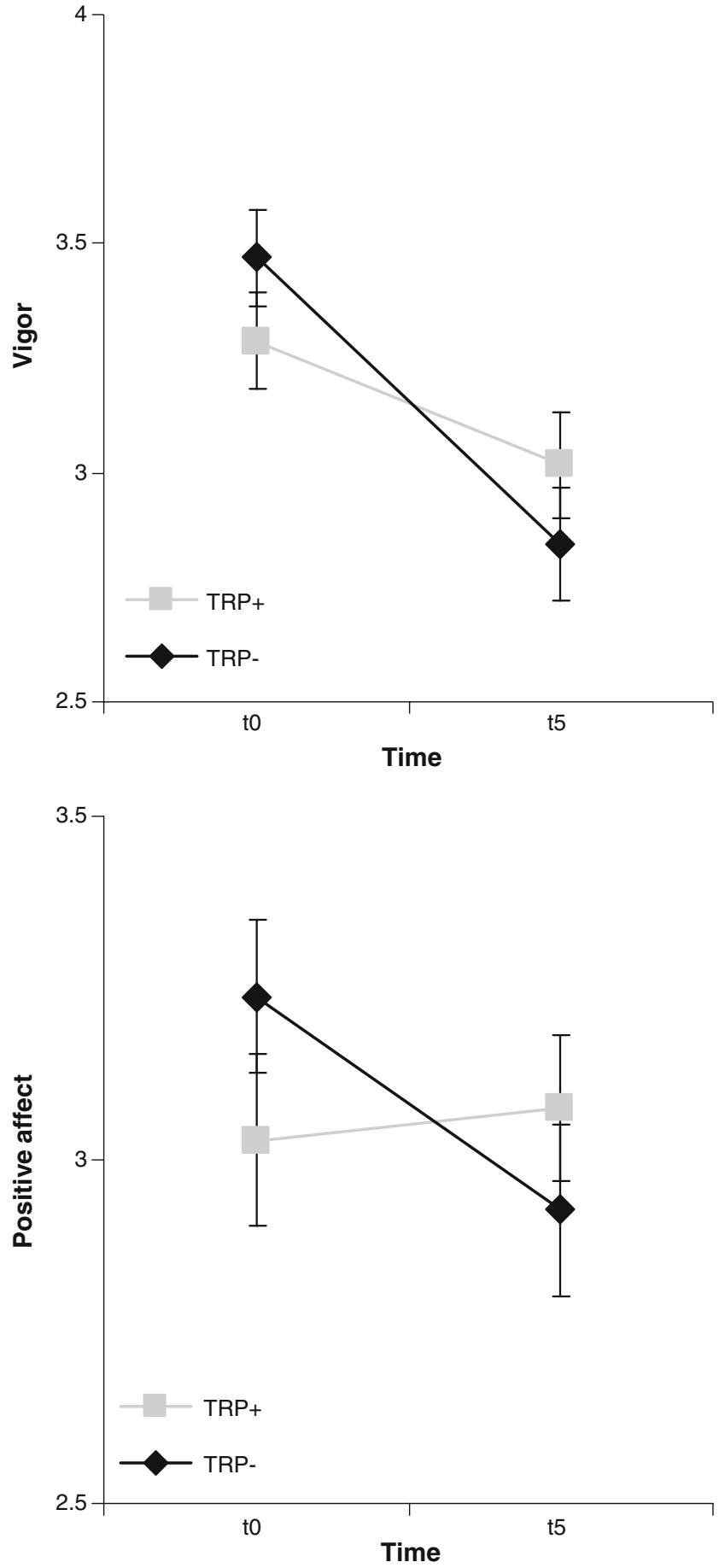

Fig. 2 Mean (SE) vigor (POMS) and positive affect (PANAS) ratings showing a significant stronger decrease in vigor ratings following TRP - than TRP $+[t(34)=2.74, p=0.01]$ and a significant decrease in positive affect ratings following TRP - but not TRP $+[t$ (34) $=2.57, p=0.015$ ]

valence $\times$ genotype interaction $[F(1,32)=8.62, p=0.006]$, reflecting significant longer RTs for sad words compared to happy words for the $\mathrm{S}^{\prime} / \mathrm{S}^{\prime}$ genotype group only $[t(17)=3.11$, $p=0.006]$ (Fig. 4).
Errors Analysis of error data revealed a main effect of treatment $[F(1,32)=4.68, p=0.038]$, indicating significantly more errors following TRP - than TRP+; a main effect of stress $[F(1,32)=4.55, p=0.041]$ with fewer errors poststress than pre-stress and a main effect of shift $[F(1,32)=$ 21.99, $p<0.001]$ with more errors for shift than non-shift blocks. Furthermore, we found a treatment $\times$ genotype $\times$ valence $\times$ shift interaction $[F(1,32)=5.27, p=0.028]$, which was explored by a three-way (treatment, valence, shift) ANOVA for each genotype revealing a treatment $\times$ valence $\times$ shift interaction for the $\mathrm{S}^{\prime} / \mathrm{S}^{\prime}$ genotype only $[F(1,16)=12.24$, $p=0.003]$. To break down this interaction, a two-way (treatment, valence) ANOVA for the $\mathrm{S}^{\prime} / \mathrm{S}^{\prime}$ genotype was
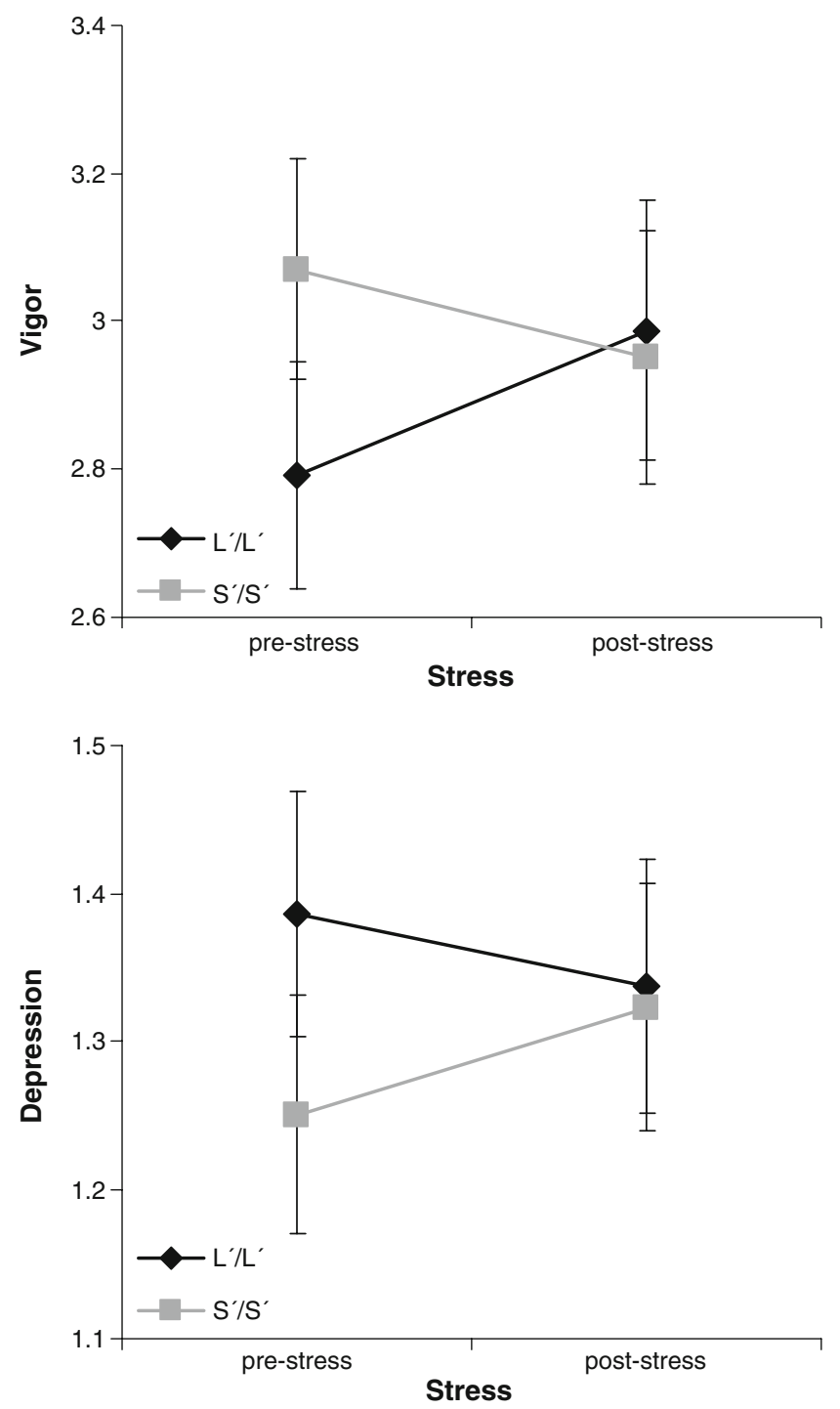

Fig. 3 Mean (SE) depression and vigor ratings pre-stress and poststress for both genotypes collapsed over treatment showing a significant increase in vigor post-stress for the $\mathrm{L}^{\prime} / \mathrm{L}^{\prime}$ genotype $[F(1$, $15)=12.61, p=0.003]$ and a significant increase in depressive mood for the $\mathrm{S}^{\prime} / \mathrm{S}^{\prime}$ genotype $[F(1,16)=5.38, p=0.034]$ 
Table 4 AGNG and memory data

\begin{tabular}{|c|c|c|c|c|c|c|c|c|c|}
\hline \multirow[t]{3}{*}{ Test } & \multirow[t]{3}{*}{ Measure } & \multicolumn{4}{|c|}{$\mathrm{L}^{\prime} / \mathrm{L}^{\prime}$ genotype } & \multicolumn{4}{|c|}{$\mathrm{S}^{\prime} / \mathrm{S}^{\prime}$ genotype } \\
\hline & & \multicolumn{2}{|l|}{ TRP+ } & \multicolumn{2}{|l|}{ TRP- } & \multicolumn{2}{|l|}{ TRP+ } & \multicolumn{2}{|l|}{ TRP- } \\
\hline & & Pre-stress & Post-stress & Pre-stress & Post-stress & Pre-stress & Post-stress & Pre-stress & Post-stress \\
\hline \multicolumn{10}{|l|}{ AGNG } \\
\hline \multirow[t]{3}{*}{ Happy shift } & RTs & $504(47)$ & $521(38)$ & $510(51)$ & $519(47)$ & $518(55)$ & $529(55)$ & $527(66)$ & $540(67)$ \\
\hline & Errors & $4.1(2.9)$ & $3.0(2.7)$ & $4.5(3.4)$ & $4.2(3.2)$ & $2.3(2.5)$ & $2.0(1.9)$ & $3.1(2.5)$ & $3.3(2.7)$ \\
\hline & Omissions & $1.9(2.0)$ & $2.1(2.5)$ & $1.6(1.4)$ & $1.3(2.4)$ & $2.9(3.0)$ & $2.8(3.2)$ & $2.2(2.9)$ & $1.6(2.2)$ \\
\hline \multirow[t]{3}{*}{ Happy non-shift } & RTs & $512(47)$ & $516(47)$ & $516(53)$ & $517(51)$ & $533(60)$ & $532(47)$ & $519(57)$ & $534(74)$ \\
\hline & Errors & $1.9(2.2)$ & $2.6(2.1)$ & $3.5(2.0)$ & $2.2(2.0)$ & $2.1(2.2)$ & $2.4(2.2)$ & $2.3(1.7)$ & $2.0(2.3)$ \\
\hline & Omissions & $1.3(1.2)$ & $1.9(2.2)$ & $2.2(1.7)$ & $1.2(2.0)$ & $1.8(1.8)$ & $1.8(1.4)$ & $2.1(2.4)$ & $2.3(1.9)$ \\
\hline \multirow[t]{3}{*}{ Sad shift } & RTs & 499 (46) & $508(52)$ & $507(44)$ & $508(45)$ & $530(62)$ & $536(59)$ & $538(63)$ & $542(74)$ \\
\hline & Errors & $3.2(3.7)$ & $2.6(2.7)$ & $3.9(3.3)$ & $2.7(3.5)$ & $3.2(3.1)$ & $3.4(2.8)$ & $2.7(3.0)$ & $2.3(2.5)$ \\
\hline & Omissions & $1.7(2.1)$ & $1.7(1.9)$ & $2.5(2.5)$ & $1.4(2.7)$ & $1.3(2.8)$ & $2.8(6.2)$ & $1.9(2.9)$ & $2.6(3.0)$ \\
\hline \multirow[t]{3}{*}{ Sad non-shift } & RTs & $515(42)$ & $527(47)$ & 509 (44) & $516(61)$ & $544(55)$ & $545(61)$ & $544(64)$ & $550(668)$ \\
\hline & Errors & $2.9(2.8)$ & $2.1(2.1)$ & $3.2(2.5)$ & $2.2(1.6)$ & $2.0(2.5)$ & $1.4(1.4)$ & $2.4(1.7)$ & $2.2(1.5)$ \\
\hline & Omissions & $1.2(1.4)$ & $0.9(1.0)$ & $1.6(1.8)$ & $1.9(2.6)$ & $1.5(1.8)$ & $3.2(6.3)$ & $1.2(2.1)$ & $2.1(2.9)$ \\
\hline \multirow[t]{8}{*}{ Memory } & \multicolumn{9}{|c|}{ Immediate recall } \\
\hline & Positive & $5.6(1.3)$ & $5.6(1.5)$ & $5.5(2.0)$ & $6.0(1.7)$ & $6.2(1.7)$ & $5.5(1.5)$ & $5.2(1.4)$ & $4.8(1.4)$ \\
\hline & Negative & $5.0(0.8)$ & $5.4(1.5)$ & $5.4(2.2)$ & $5.4(1.9)$ & $4.6(1.5)$ & $4.4(2.2)$ & $4.1(1.3)$ & $4.6(1.4)$ \\
\hline & Neutral & $6.1(1.7)$ & $4.8(1.7)$ & $4.4(1.8)$ & $4.9(2.1)$ & $4.6(1.9)$ & $4.3(2.2)$ & $4.4(1.5)$ & $4.3(1.8)$ \\
\hline & \multicolumn{9}{|c|}{ Delayed recall } \\
\hline & Positive & $5.4(1.7)$ & $5.0(1.5)$ & $5.4(2.1)$ & $4.9(1.9)$ & $5.6(1.9)$ & $4.7(1.6)$ & $4.9(1.6)$ & $3.9(1.6)$ \\
\hline & Negative & $4.2(1.1)$ & $3.9(1.1)$ & $4.4(1.8)$ & $4.0(1.8)$ & $4.3(1.2)$ & $3.4(2.1)$ & $3.7(1.6)$ & $3.1(1.1)$ \\
\hline & Neutral & $5.1(2.0)$ & $3.2(1.7)$ & $4.2(1.8)$ & $4.2(1.7)$ & $4.4(2.0)$ & $3.4(2.1)$ & $3.8(1.7)$ & $3.1(1.9)$ \\
\hline
\end{tabular}

Values represent mean (SD)

run for each shift condition showing a treatment $\times$ valence interaction for the shift condition only $[F(1,16)=9.19, p=$ 0.008], revealing more errors following TRP- than TRP+ during happy shift blocks $[t(17)=2.15, p=0.047]$.

Further, a treatment $\times$ stress $\times$ valence $\times$ shift interaction $[F(1,32)=13.01, p=0.001]$ was found reflecting a treatment $\times$ stress $\times$ valence interaction for the non-shift condition only $[F(1,33)=8.45, p=0.006]$. This interaction was further explored by a two-way (treatment, stress) ANOVA for happy words and sad words yielding a treatment $\times$ stress interaction for happy words only $[F(1$, $33)=12.62, p=0.001]$, showing a decrease in errors prestress to post-stress following TRP $-[t(34)=2.52, p=0.017]$ but no effect following TRP $+[t(34)=1.67, p=0.10]$.

Omissions Analysis of omission data revealed a significant treatment $\times$ valence $\times$ shift interaction $[F(1,32)=4.66, p=$ 0.038]. A two-way (treatment, valence) ANOVA was run for shift and non-shift blocks revealing a marginally significant treatment $\times$ valence interaction for the shift blocks only $[F(1,33)=3.98, p=0.054]$, indicating more omissions for happy shift trials following TRP+ compared to TRP-. However, this difference did not approach significance $[t(34)=1.78, p=0.085]$. There were no effects of genotype or stress.

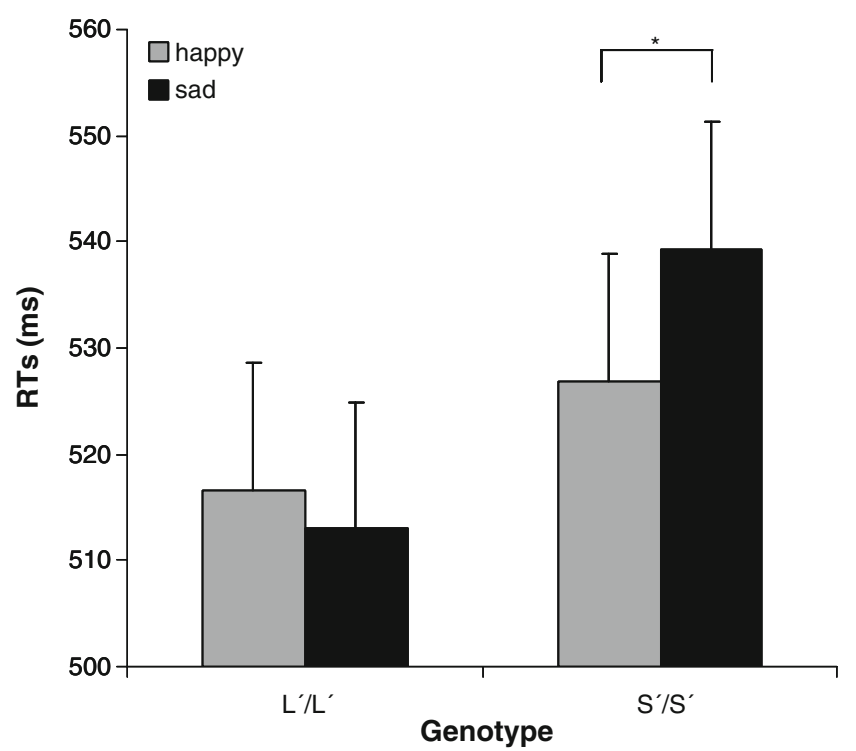

Fig. 4 Mean RTs (SE) for happy and sad target words for both genotypes collapsed over stress showing significant longer RTs for sad words compared to happy words for the $\mathrm{S}^{\prime} / \mathrm{S}^{\prime}$ genotype group only $[t$ (17) $=3.11, p=0.006$ ] 
Emotionally related free recall

Mean values and standard deviations are presented in Table 4.

Immediate recall Analysis of immediate recall data revealed a main effect of valence $[F(2,64)=11.38, p<$ $0.001]$ and a significant genotype $\times$ treatment $\times$ valence interaction $[F(2,64)=4.17, p=0.02]$. This interaction was explored by a two-way ANOVA (treatment, genotype) for positive, negative, and neutral words, revealing a marginally significant treatment $\times$ genotype interaction for positive words only $[F(1,32)=3.48, p=0.071]$. This interaction, which is visualized in Fig. 5, reflected that individuals with the $\mathrm{S}^{\prime} / \mathrm{S}^{\prime}$ genotype recalled fewer positive words following TRP - than TRP $+[t(17)=2.5, p=0.023]$.

Delayed recall An analysis of the delayed recall data revealed a main effect of stress $[F(1,32)=14.57, p=$ $0.001]$ reflecting that fewer words were recalled post-stress than pre-stress, and a main effect of valence $[F(2,64)=$ $54.17, p<0.001]$ showing that more positive words were recalled than negative and neutral words. Further, we found a significant treatment $\times$ stress $\times$ valence interaction $[F(2$, $64)=3.28, p=0.049]$. This interaction was further explored by a two-way (treatment, stress) ANOVA for positive, negative, and neutral words, revealing a treatment $\times$ stress interaction for neutral words only $[F(1,33)=7.45, p=0.01]$, indicating that more neutral words were recalled pre-stress compared post-stress following TRP $+[t(34)=4.37, p=$ $0.000]$ but not TRP- $[t(34)<1, \mathrm{~ns}]$. However, it should be noted that there was already a difference between treat-

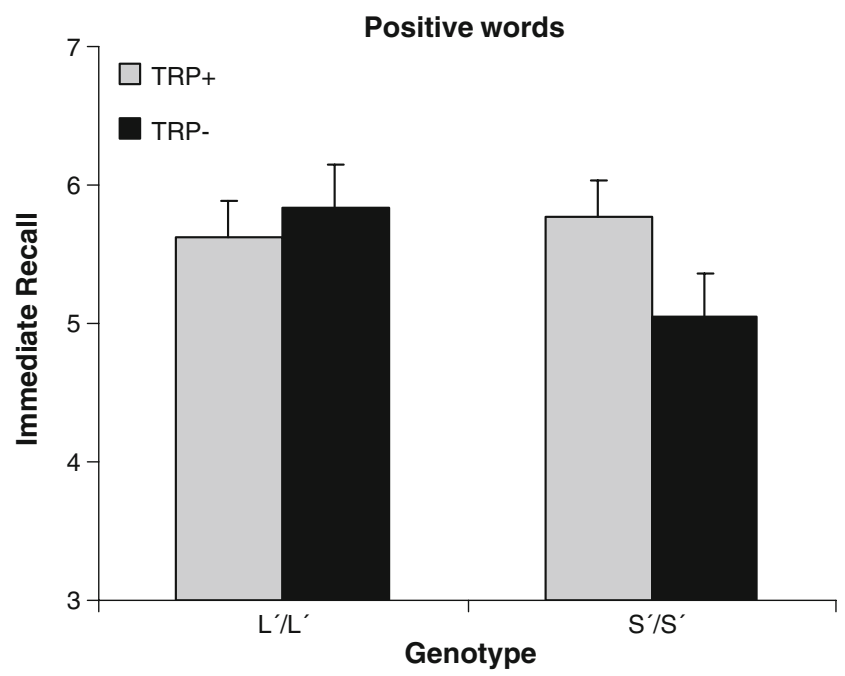

Fig. 5 Mean number (SE) of immediately recalled positive words for both genotypes following TRP+ and TRP- collapsed over stress showing that individuals with the $\mathrm{S}^{\prime} / \mathrm{S}^{\prime}$ genotype recalled fewer positive words following TRP - than TRP $+[t(17)=2.5, p=0.023]$ ments pre-stress $[t(34)=2.2, p=0.034]$ with fewer neutral words being recalled following TRP- than TRP+.

\section{Discussion}

The goal of the present study was to assess mood, memory, and attention in individuals with different 5-HTTLPR genotypes following ATD before and after the exposure to uncontrollable stress.

ATD lowered the plasma TRP/LNAA by $77 \%$, which is comparable with previous studies using the same CP ATD method (Evers et al. 2005) or the classic ATD mixture (Van der Does 2001). Previous studies using the classic ATD mixture have reported an increase in plasma TRP of up to $200 \%$ in the balanced (TRP+) condition (for a review see Fusar-Poli et al. 2006), whereas the CP ATD method has been found to be more effective in maintaining a stable TRP+ condition (Evers et al. 2005; Firk and Markus 2008). In the present study, the TRP/LNAA ratio also increased by $62 \%$ in the TRP+ condition suggesting that the TRP+ condition may also be psychoactive due to an increase in 5HT synthesis. However, this increase in TRP/LNAA ratio is probably insufficient to affect behavior (Markus 2008).

ATD resulted in a significant reduction of positive mood in all subjects independent of 5-HTTLPR genotype. This finding was surprising since most studies only found moodlowering effects of ATD in individuals at risk for depression such as depressive patients in remission, individuals with a positive family history of depression (for a recent review see Ruhe et al. 2007), or in healthy s allele carries as compared to 1 carriers (Neumeister et al. 2002, 2006). However, few recent studies including the triallelic 5HTTLPR polymorphism also revealed negative mood effects of ATD in $1 / 1$ carriers if they were patients (Neumeister et al. 2006) or women (Walderhaug et al. 2007). Although our participants reported no family history of depression during screening, it may indeed be possible that some of these answers were instead based on lack of information, which may also explain this surprising effect. However, even if one or two young adult participants were actually $\mathrm{FH}+$, it is unlikely that this has confounded our findings given the sample size of the current study.

Even though the $\mathrm{s}$ allele is suggested as a vulnerability factor for the negative effects of ATD on mood, it seems that this is more complex and brain 5-HT manipulation may particularly alter mood in $\mathrm{s}$ allele carriers when the serotonergic system is actually needed in the face of acute stress as 5-HT plays a role in regulating HPA axis activity, which is important for stress coping (e.g., Porter et al. 2004). Therefore, we predicted that $\mathrm{s}$ allele carriers are especially vulnerable to ATD under acute stress exposure. For this purpose, the MPA task was used in the present 
study as an uncontrollable stress situation since it has frequently been found to induce stress as indicated by mood deterioration and increases in cortisol and electrophysiological arousal (e.g., Markus et al. 2002; Peters et al. 1998). Analysis indeed revealed a slight stress-induced increase in depression scores exclusively in $\mathrm{S}^{\prime} / \mathrm{S}^{\prime}$ genotypes, whereas in $\mathrm{L}^{\prime} / \mathrm{L}^{\prime}$ genotypes stress even increased positive feelings of vigor. These findings seem to support previous assumptions of 5-HTTLPR s allele as a vulnerability factor in the development of depression and suggest that $\mathrm{L}^{\prime} / \mathrm{L}^{\prime}$ carriers are less susceptible to the negative effects of stress than $S^{\prime} / S^{\prime}$ genotypes. As already described in the "Introduction", 5HT plays an important role in stress coping which may explain why 1 allele carriers are more resistant to the negative effects of stress compared to s allele carriers. This involvement of 5-HT in stress coping is supported by complex interactions between 5-HT and the neuroendocrine stress system (Porter et al. 2004). Acute stress increases 5HT neurotransmission (Davis et al. 1995; De Kloet et al. 1982, 1983), which promotes stress adaptation by mediating negative feedback control of cortisol on the HPA axis (Nuller and Ostroumova 1980; Van Praag 2004). In accord with the current findings, s allele carriers are thought to be 5-HT vulnerable and to be susceptible to depression symptoms particularly in the face of stress (Caspi et al. 2003; Firk and Markus 2007; Van Praag 2004). Although hypothetically, stress and enhanced HPA activation, particularly in s allele carriers, may further undermine 5-HT function, which then may lead to reduced stress coping and subsequently result in negative mood (e.g., Dayan and Huys 2008; Firk and Markus 2007; Van Praag 2004). In further support, Gotlib et al. (2008) found that only girls homozygous for the s allele showed a cortisol response following acute stress exposure, which also supports the hypothesis that 5-HTTLPR affects HPA activity and hence, stress reactivity.

Although the affective effects of acute stress exposure appear to be influenced by 5-HTTLPR, there was no additional effect of ATD. Assuming that $\mathrm{S}^{\prime} / \mathrm{S}^{\prime}$ genotypes have a greater serotonergic vulnerability than $\mathrm{L}^{\prime} / \mathrm{L}^{\prime}$ genotypes, and that sufficient 5-HT function is a biological basis for stress coping, we expected that ATD would further increase the negative effect of stress exposure in $\mathrm{S}^{\prime} / \mathrm{S}^{\prime}$ genotypes. This absence of interaction between ATD, stress, and 5-HTTLPR on depression scores might well be explained by the apparent modest effect of the current acute stress task. Although the MPA stress task also affected mood in the current study, cortisol responses were not increased following stress exposure, suggesting that the MPA task, in the present study, was only a brief and mild stressor. On the contrary, Gotlib et al. (2008) found a 5HTTLPR-mediated change in cortisol responses by including a more severe and sustained stress procedure. Therefore,
ATD may only mediate stress-induced affective changes in s allele carriers under highly emotionally (depression) relevant stressful conditions that require enhanced activation of 5-HT-involved adaptation mechanisms. A1though in the current study design, stress may be confounded with fatigue effects over time, subjective mood ratings showed that fatigue decreases post-stress compared to pre-stress, suggesting that stress was not meaningfully confounded by fatigue over time in the current study.

Based on previous studies reporting memory (e.g., Rinck and Becker 2005) and attention bias (e.g., Murphy et al. 1999) toward negatively toned material in depressive patients, we expected a negative attention and memory bias for $\mathrm{S}^{\prime} / \mathrm{S}^{\prime}$ genotypes especially following ATD and stress exposure. On the AGNG task, we expected faster RTs when responding to sad words; however, slower RTs were found for sad words compared to happy words for $\mathrm{S}^{\prime} / \mathrm{S}^{\prime}$ genotypes. One possible explanation for this is that $S^{\prime} / S^{\prime}$ genotypes might have a pre-clinical baseline disposition to avoid negative information to counteract heightened amygdala responsivity to negative information (Hariri et al. 2005; Heinz et al. 2005; Pezawas et al. 2005). In support of this theory, avoidance behavior is generally recognized as a mediating factor in anxiety disorders and in the onset of depression (Tull and Gratz 2008). Another possible explanation might be that $\mathrm{S}^{\prime} / \mathrm{S}^{\prime}$ genotypes spend more time on the elaboration of negative material which might increase their vulnerability to depression. In support of this, healthy individuals without any vulnerability to depression actively avoid elaboration of negative stimuli while depressed patients fail to do so (Deveney and Deldin 2004). This is also consistent with a recently described neuro-computational model by Dayan and Huys (2008). In their model, 5-HT modulates behavioral inhibition as a Pavlovian control process suppressing negative representations that may lead to aversive states and consequences. By reducing brain 5-HT through ATD, this control process will fail and subsequently will give free rein to negative thoughts and actions. Further, in terms of this model, ATD might decrease suppression of negative thoughts particularly in $\mathrm{S}^{\prime} / \mathrm{S}^{\prime}$ genotypes due to serotonergic vulnerability that is caused by higher 5-HT levels throughout the lifespan development as a function of less sufficient 5-HT reuptake (Dayan and Huys 2008). However, in the present study, ATD did not affect RTs, and increased the number of errors during happy shift blocks only in $\mathrm{S}^{\prime} / \mathrm{S}^{\prime}$ genotypes, suggesting a slightly increased ATD vulnerability for $\mathrm{S}^{\prime} / \mathrm{S}^{\prime}$ genotypes in line with our expectations. Previous findings from ATD studies in healthy subjects were inconsistent: some showed a negative attention bias following ATD (Murphy et al. 2002), others reported a bias toward positive material following ATD (Hayward et al. 2005) and others 
did not find a differential effect of ATD on emotional processing (Roiser et al. 2007; Rubinsztein et al. 2001).

On the memory task, ATD impaired immediate recall of positive words in $\mathrm{S}^{\prime} / \mathrm{S}^{\prime}$ genotypes. This indeed resembles the mood-congruent memory bias that has been reported for depressed patients reflecting impaired memory for positive information (Matt et al. 1992). Memory performance following ATD has been investigated in previous studies reporting impaired recall of positive words following ATD in healthy subjects (Klaassen et al. 2002) and impaired recall in healthy $S^{\prime} / S^{\prime}$ genotypes independent of word valence (Roiser et al. 2007). Thus, ATD impairs memory performance and in the present study even induces a depressive-like memory pattern in $\mathrm{S}^{\prime} / \mathrm{S}^{\prime}$ carriers following ATD, supporting greater vulnerability of $\mathrm{S}^{\prime} / \mathrm{S}^{\prime}$ carriers to depression.

To conclude, polymorphisms of the 5-HTTLPR differentially affects responses to mild stress and ATD, suggesting greater vulnerability of $\mathrm{S}^{\prime} / \mathrm{S}^{\prime}$ carriers to serotonergic manipulations and supporting increased depression vulnerability. The absence of interaction between ATD, stress, and 5-HTTLPR, possibly due to the modest effect of the current acute stress task, merits further research using a stronger and a more sustained stress procedure.

Acknowledgments We thank Anja Keitel, Sarah Bourdon, Jasper Engels, and Janneke Guijaux for assistance in running the experiment.

\section{Conflict of interest statement None.}

Open Access This article is distributed under the terms of the Creative Commons Attribution Noncommercial License which permits any noncommercial use, distribution, and reproduction in any medium, provided the original author(s) and source are credited.

\section{References}

Beck AT, Ward CH, Mendelson M, Mock J, Erbaugh J (1961) An inventory for measuring depression. Arch Gen Psychiatry 4:561571

Benkelfat C, Ellenbogen MA, Dean P, Palmour RM, Young SN (1994) Mood-lowering effect of tryptophan depletion. Enhanced susceptibility in young men at genetic risk for major affective disorders. Arch Gen Psychiatry 51:687-697

Blokland A, Lieben C, Deutz NEP, Schmitt J (2004) Acute tryptophan depletion: comparing the effects of an amino acid mixture with a gelatin-based protein in man and rats. Curr Top Nutraceutical Res 2:161-169

Bradley BP, Mogg K, Williams R (1995) Implicit and explicit memory for emotion-congruent information in clinical depression and anxiety. Behav Res Ther 33:755-770

Carpenter LL, Anderson GM, Pelton GH, Gudin JA, Kirwin PD, Price LH, Heninger GR, McDougle CJ (1998) Tryptophan depletion during continuous CSF sampling in healthy human subjects. Neuropsychopharmacology 19:26-35
Caspi A, Sugden K, Moffitt TE, Taylor A, Craig IW, Harrington H, McClay J, Mill J, Martin J, Braithwaite A, Poulton R (2003) Influence of life stress on depression: moderation by a polymorphism in the 5-HTT gene. Science 301:386-389

Collier DA, Stober G, Li T, Heils A, Catalano M, Di Bella D, Arranz MJ, Murray RM, Vallada HP, Bengel D, Muller CR, Roberts GW, Smeraldi E, Kirov G, Sham P, Lesch KP (1996) A novel functional polymorphism within the promoter of the serotonin transporter gene: possible role in susceptibility to affective disorders. Mol Psychiatry 1:453-460

Davis S, Heal DJ, Stanford SC (1995) Long-lasting effects of an acute stress on the neurochemistry and function of 5-hydroxytryptaminergic neurones in the mouse brain. Psychopharmacology (Berl) 118:267-272

Dayan P, Huys QJ (2008) Serotonin, inhibition, and negative mood. PLoS Comput Biol 4:e4

De Kloet ER, Kovacs GL, Szabo G, Telegdy G, Bohus B, Versteeg DH (1982) Decreased serotonin turnover in the dorsal hippocampus of rat brain shortly after adrenalectomy: selective normalization after corticosterone substitution. Brain Res 239: 659-663

De Kloet ER, Versteeg DH, Kovacs GL (1983) Aldosterone blocks the response to corticosterone in the raphe-hippocampal serotonin system. Brain Res 264:323-327

Delgado PL, Charney DS, Price LH, Aghajanian GK, Landis H, Heninger GR (1990) Serotonin function and the mechanism of antidepressant action. Reversal of antidepressant-induced remission by rapid depletion of plasma tryptophan. Arch Gen Psychiatry 47:411-418

Delgado PL, Miller HL, Salomon RM, Licinio J, Krystal JH, Moreno FA, Heninger GR, Charney DS (1999) Tryptophan-depletion challenge in depressed patients treated with desipramine or fluoxetine: implications for the role of serotonin in the mechanism of antidepressant action. Biol Psychiatry 46:212-220

Deveney CM, Deldin PJ (2004) Memory of faces: a slow wave ERP study of major depression. Emotion 4:295-304

Erickson K, Drevets WC, Clark L, Cannon DM, Bain EE, Zarate CA, Jr., Charney DS, Sahakian BJ (2005) Mood-congruent bias in affective go/no-go performance of unmedicated patients with major depressive disorder. Am J Psychiatry 162:2171-2173

Evers EA, Tillie DE, van der Veen FM, Lieben CK, Jolles J, Deutz NE, Schmitt JA (2005) Effects of a novel method of acute tryptophan depletion on plasma tryptophan and cognitive performance in healthy volunteers. Psychopharmacology (Berl) 178:92-99

Fernstrom JD, Wurtman RJ (1971) Brain serotonin content: physiological dependence on plasma tryptophan levels. Science 173:149-152

Firk C, Markus CR (2007) Review: Serotonin by stress interaction: a susceptibility factor for the development of depression? J Psychopharmacol 21:538-544

Firk C, Markus CR (2008) Effects of acute tryptophan depletion on affective processing in first-degree relatives of depressive patients and controls after exposure to uncontrollable stress. Psychopharmacology (Berl) 199:151-160

Fusar-Poli P, Allen P, McGuire P, Placentino A, Cortesi M, Perez J (2006) Neuroimaging and electrophysiological studies of the effects of acute tryptophan depletion: a systematic review of the literature. Psychopharmacology (Berl) 188:131-143

Gessa GL, Biggio G, Fadda F, Corsini GU, Tagliamonte A (1974) Effect of the oral administration of tryptophan-free amino acid mixtures on serum tryptophan, brain tryptophan and serotonin metabolism. J Neurochem 22:869-870

Gonda X, Juhasz G, Laszik A, Rihmer Z, Bagdy G (2005) Subthreshold depression is linked to the functional polymorphism of the 5HT transporter gene. J Affect Disord 87:291-297 
Gonda X, Rihmer Z, Zsombok T, Bagdy G, Akiskal KK, Akiskal HS (2006) The 5HTTLPR polymorphism of the serotonin transporter gene is associated with affective temperaments as measured by TEMPS-A. J Affect Disord 91:125-131

Gotlib IH, Joormann J, Minor KL, Hallmayer J (2008) HPA axis reactivity: a mechanism underlying the associations among 5HTTLPR, stress, and depression. Biol Psychiatry 63:847-51

Greenberg BD, Tolliver TJ, Huang SJ, Li Q, Bengel D, Murphy DL (1999) Genetic variation in the serotonin transporter promoter region affects serotonin uptake in human blood platelets. Am J Med Genet 88:83-87

Hariri AR, Mattay VS, Tessitore A, Kolachana B, Fera F, Goldman D, Egan MF, Weinberger DR (2002) Serotonin transporter genetic variation and the response of the human amygdala. Science 297:400-403

Hariri AR, Drabant EM, Munoz KE, Kolachana BS, Mattay VS, Egan MF, Weinberger DR (2005) A susceptibility gene for affective disorders and the response of the human amygdala. Arch Gen Psychiatry 62:146-152

Hayward G, Goodwin GM, Cowen PJ, Harmer CJ (2005) Low-dose tryptophan depletion in recovered depressed patients induces changes in cognitive processing without depressive symptoms. Biol Psychiatry 57:517-524

Heils A, Teufel A, Petri S, Stober G, Riederer P, Bengel D, Lesch KP (1996) Allelic variation of human serotonin transporter gene expression. J Neurochem 66:2621-2624

Heinz A, Braus DF, Smolka MN, Wrase J, Puls I, Hermann D, Klein S, Grusser SM, Flor H, Schumann G, Mann K, Buchel C (2005) Amygdala-prefrontal coupling depends on a genetic variation of the serotonin transporter. Nat Neurosci 8:20-21

Hermans D, De Houwer J (1994) Affective and subjective familiarity ratings of 740 Dutch words. Psychologica Belgica 34:115-139

Hu XZ, Lipsky RH, Zhu G, Akhtar LA, Taubman J, Greenberg BD, $\mathrm{Xu} \mathrm{K}$, Arnold PD, Richter MA, Kennedy JL, Murphy DL, Goldman D (2006) Serotonin transporter promoter gain-offunction genotypes are linked to obsessive-compulsive disorder. Am J Hum Genet 78:815-826

Joiner TE Jr, Johnson F, Soderstrom K, Brown JS (2003) Is there an association between serotonin transporter gene polymorphism and family history of depression? J Affect Disord 77:273-275

Klaassen T, Riedel WJ, van Someren A, Deutz NE, Honig A, van Praag HM (1999) Mood effects of 24-hour tryptophan depletion in healthy first-degree relatives of patients with affective disorders. Biol Psychiatry 46:489-497

Klaassen T, Riedel WJ, Deutz NE, Van Praag HM (2002) Mood congruent memory bias induced by tryptophan depletion. Psychol Med 32:167-172

Lesch KP, Balling U, Gross J, Strauss K, Wolozin BL, Murphy DL, Riederer P (1994) Organization of the human serotonin transporter gene. J Neural Transm Gen Sect 95:157-162

Lezak MD (2004) Auditory-verbal learning test (AVLT). In: Lezak MD, Howieson DB, Loring DW (eds) Neuropsychological assessment, 4th edn. Oxford University Press, London, pp 422-429

Lim SL, Kim JH (2005) Cognitive processing of emotional information in depression, panic, and somatoform disorder. J Abnorm Psychol 114:50-61

Lotrich FE, Pollock BG (2004) Meta-analysis of serotonin transporter polymorphisms and affective disorders. Psychiatr Genet 14:121-129

Maes M, Meltzer HY (1995) The serotonin hypothesis of major depression. In: Bloom FE, Kupfer DJ (eds) Psychopharmacology: the fourth generation of progress. Raven, New York, pp 933944

Markus CR (2008) Dietary amino acids and brain serotonin function; implications for stress-related affective changes. Neuromolecular Med (in press). doi:10.1007/s12017-008-8039-9
Markus CR, Panhuysen G, Tuiten A, Koppeschaar H, Fekkes D, Peters ML (1998) Does carbohydrate-rich, protein-poor food prevent a deterioration of mood and cognitive performance of stress-prone subjects when subjected to a stressful task? Appetite $31: 49-65$

Markus CR, Olivier B, Panhuysen GE, Van Der Gugten J, Alles MS, Tuiten A, Westenberg HG, Fekkes D, Koppeschaar HF, de Haan EE (2000a) The bovine protein alpha-lactalbumin increases the plasma ratio of tryptophan to the other large neutral amino acids, and in vulnerable subjects raises brain serotonin activity, reduces cortisol concentration, and improves mood under stress. Am J Clin Nutr 71:1536-1544

Markus CR, Panhuysen G, Tuiten A, Koppeschaar H (2000b) Effects of food on cortisol and mood in vulnerable subjects under controllable and uncontrollable stress. Physiol Behav 70:333-342

Markus CR, Olivier B, de Haan EH (2002) Whey protein rich in alpha-lactalbumin increases the ratio of plasma tryptophan to the sum of the other large neutral amino acids and improves cognitive performance in stress-vulnerable subjects. Am J Clin Nutr 75:1051-1056

Marsh AA, Finger EC, Buzas B, Soliman N, Richell RA, Vythilingham M, Pine DS, Goldman D, Blair RJ (2006) Impaired recognition of fear facial expressions in 5-HTTLPR S-polymorphism carriers following tryptophan depletion. Psychopharmacology (Berl) 189:387-394

Matt GE, Vazquez C, Campbell WK (1992) Mood-congruent recall of affectively toned stimuli: a meta-analytic review. Clin Psychol Rev 12:227-255

Meyer JH, Wilson AA, Sagrati S, Hussey D, Carella A, Potter WZ, Ginovart N, Spencer EP, Cheok A, Houle S (2004) Serotonin transporter occupancy of five selective serotonin reuptake inhibitors at different doses: an [11C]DASB positron emission tomography study. Am J Psychiatry 161:826-835

Mogg K, Bradley BP (2005) Attentional bias in generalized anxiety disorder versus depressive disorder. Cogn Ther Res 29:29-45

Moja EA, Rocchi E, Benedetti F, Paolillo F, Casalgrandi G, Ponz de Leon M (1991) Decrease in plasma tryptophan after a tryptophanfree amino acid solution. A comparison between cirrhotic and control subjects. Life Sci 48:409-418

Moreno FA, Heninger GR, McGahuey CA, Delgado PL (2000) Tryptophan depletion and risk of depression relapse: a prospective study of tryptophan depletion as a potential predictor of depressive episodes. Biol Psychiatry 48:327-329

Murphy FC, Sahakian BJ, Rubinsztein JS, Michael A, Rogers RD, Robbins TW, Paykel ES (1999) Emotional bias and inhibitory control processes in mania and depression. Psychol Med 29: $1307-1321$

Murphy FC, Smith KA, Cowen PJ, Robbins TW, Sahakian BJ (2002) The effects of tryptophan depletion on cognitive and affective processing in healthy volunteers. Psychopharmacology (Berl) 163:42-53

Neumeister A, Konstantinidis A, Stastny J, Schwarz MJ, Vitouch O, Willeit M, Praschak-Rieder N, Zach J, de Zwaan M, Bondy B, Ackenheil M, Kasper S (2002) Association between serotonin transporter gene promoter polymorphism (5HTTLPR) and behavioral responses to tryptophan depletion in healthy women with and without family history of depression. Arch Gen Psychiatry 59:613-620

Neumeister A, Young T, Stastny J (2004) Implications of genetic research on the role of the serotonin in depression: emphasis on the serotonin type 1A receptor and the serotonin transporter. Psychopharmacology (Berl) 174:512-524

Neumeister A, Hu XZ, Luckenbaugh DA, Schwarz M, Nugent AC, Bonne O, Herscovitch P, Goldman D, Drevets WC, Charney DS (2006) Differential effects of 5-HTTLPR genotypes on the behavioral and neural responses to tryptophan depletion in 
patients with major depression and controls. Arch Gen Psychiatry 63:978-986

Nuller JL, Ostroumova MN (1980) Resistance to inhibiting effect of dexamethasone in patients with endogenous depression. Acta Psychiatr Scand 61:169-177

Peters ML, Godaert GL, Ballieux RE, van Vliet M, Willemsen JJ, Sweep FC, Heijnen CJ (1998) Cardiovascular and endocrine responses to experimental stress: effects of mental effort and controllability. Psychoneuroendocrinology 23:1-17

Pezawas L, Meyer-Lindenberg A, Drabant EM, Verchinski BA, Munoz KE, Kolachana BS, Egan MF, Mattay VS, Hariri AR, Weinberger DR (2005) 5-HTTLPR polymorphism impacts human cingulate-amygdala interactions: a genetic susceptibility mechanism for depression. Nat Neurosci 8:828-834

Porter RJ, Gallagher P, Watson S, Young AH (2004) Corticosteroidserotonin interactions in depression: a review of the human evidence. Psychopharmacology (Berl) 173:1-17

Riedel WJ, Klaassen T, Deutz NE, van Someren A, van Praag HM (1999) Tryptophan depletion in normal volunteers produces selective impairment in memory consolidation. Psychopharmacology (Berl) 141:362-369

Rinck M, Becker ES (2005) A comparison of attentional biases and memory biases in women with social phobia and major depression. J Abnorm Psychol 114:62-74

Roiser JP, Cook LJ, Cooper JD, Rubinsztein DC, Sahakian BJ (2005) Association of a functional polymorphism in the serotonin transporter gene with abnormal emotional processing in ecstasy users. Am J Psychiatry 162:609-612

Roiser JP, Blackwell AD, Cools R, Clark L, Rubinsztein DC, Robbins TW, Sahakian BJ (2006) Serotonin transporter polymorphism mediates vulnerability to loss of incentive motivation following acute tryptophan depletion. Neuropsychopharmacology 31(10): 2264-2272

Roiser JP, Muller U, Clark L, Sahakian BJ (2007) The effects of acute tryptophan depletion and serotonin transporter polymorphism on emotional processing in memory and attention. Int $\mathrm{J}$ Neuropsychopharmacol 10:449-461

Rubinsztein JS, Rogers RD, Riedel WJ, Mehta MA, Robbins TW, Sahakian BJ (2001) Acute dietary tryptophan depletion impairs maintenance of "affective set" and delayed visual recognition in healthy volunteers. Psychopharmacology (Berl) 154:319-326

Ruhe HG, Mason NS, Schene AH (2007) Mood is indirectly related to serotonin, norepinephrine and dopamine levels in humans: a meta-analysis of monoamine depletion studies. Mol Psychiatry 12:331-359

Sambeth A, Riedel WJ, Tillie DE, Blokland A, Postma A, Schmitt JA (2008) Memory impairments in humans after acute tryptophan depletion using a novel gelatin-based protein drink. J Psychopharmacol (in press). doi:10.1177/0269881108089577

Serretti A, Mandelli L, Lorenzi C, Pirovano A, Olgiati P, Colombo C, Smeraldi E (2007) Serotonin transporter gene influences the time course of improvement of "core" depressive and somatic anxiety symptoms during treatment with SSRIs for recurrent mood disorders. Psychiatry Res 149:185-193

Smeets T, Jelicic M, Merckelbach H (2006) The effect of acute stress on memory depends on word valence. Int J Psychophysiol 62:30-37

Smeraldi E, Zanardi R, Benedetti F, Di Bella D, Perez J, Catalano M (1998) Polymorphism within the promoter of the serotonin transporter gene and antidepressant efficacy of fluvoxamine. Mol Psychiatry 3:508-511

Sobczak S, Honig A, Nicolson NA, Riedel WJ (2002a) Effects of acute tryptophan depletion on mood and cortisol release in firstdegree relatives of type I and type II bipolar patients and healthy matched controls. Neuropsychopharmacology 27:834-842

Sobczak S, Riedel WJ, Booij I, Aan Het Rot M, Deutz NE, Honig A (2002b) Cognition following acute tryptophan depletion: difference between first-degree relatives of bipolar disorder patients and matched healthy control volunteers. Psychol Med 32:503-515

Suhara T, Takano A, Sudo Y, Ichimiya T, Inoue M, Yasuno F, Ikoma Y, Okubo Y (2003) High levels of serotonin transporter occupancy with low-dose clomipramine in comparative occupancy study with fluvoxamine using positron emission tomography. Arch Gen Psychiatry 60:386-391

Tull MT, Gratz KL (2008) Further examination of the relationship between anxiety sensitivity and depression: the mediating role of experiential avoidance and difficulties engaging in goal-directed behavior when distressed. J Anxiety Disord 22:199-210

Uher R, McGuffin P (2008) The moderation by the serotonin transporter gene of environmental adversity in the aetiology of mental illness: review and methodological analysis. Mol Psychiatry 13:131-146

Van der Does AJ (2001) The effects of tryptophan depletion on mood and psychiatric symptoms. J Affect Disord 64:107-119

Van Praag HM (2004) Can stress cause depression? Prog Neuropsychopharmacol Biol Psychiatry 28:891-907

Voineskos AN, Wilson AA, Boovariwala A, Sagrati S, Houle S, Rusjan P, Sokolov S, Spencer EP, Ginovart N, Meyer JH (2007) Serotonin transporter occupancy of high-dose selective serotonin reuptake inhibitors during major depressive disorder measured with [(11)C]DASB positron emission tomography. Psychopharmacology (Berl) 193:539-545

Wald FDM, Mellenbergh GJ (1990) De verkorte versie van de Nederlandse vertaling van de Profile of Mood States (POMS). Ned Tijdschr Psychol 45:86-90

Walderhaug E, Magnusson A, Neumeister A, Lappalainen J, Lunde H, Refsum H, Landro NI (2007) Interactive effects of sex and 5HTTLPR on mood and impulsivity during tryptophan depletion in healthy people. Biol Psychiatry 62:593-599

Watson D, Clark LA, Tellegen A (1988) Development and validation of brief measures of positive and negative affect: the PANAS scales. J Pers Soc Psychol 54:1063-1070

Wendland JR, Martin BJ, Kruse MR, Lesch KP, Murphy DL (2006) Simultaneous genotyping of four functional loci of human SLC6A4, with a reappraisal of 5-HTTLPR and rs25531. Mol Psychiatry 11:224-226

Williams WA, Shoaf SE, Hommer D, Rawlings R, Linnoila M (1999) Effects of acute tryptophan depletion on plasma and cerebrospinal fluid tryptophan and 5-hydroxyindoleacetic acid in normal volunteers. J Neurochem 72:1641-1647

Young SN, Smith SE, Pihl RO, Ervin FR (1985) Tryptophan depletion causes a rapid lowering of mood in normal males. Psychopharmacology (Berl) 87:173-177

Zalsman G, Huang YY, Oquendo MA, Burke AK, Hu XZ, Brent DA, Ellis SP, Goldman D, Mann JJ (2006) Association of a triallelic serotonin transporter gene promoter region (5-HTTLPR) polymorphism with stressful life events and severity of depression. Am J Psychiatry 163:1588-1593 